\title{
The Red Atrapa Sismos (Quake-Catcher Network in Mexico): Assessing Performance during Large and Damaging Earthquakes
}

\section{by Luis A. Dominguez, Battalgazi Yildirim, Allen L. Husker, Elizabeth Cochran, Carl Christensen, Victor M. Cruz-Atienza, and Jesse F. Lawrence}

\section{INTRODUCTION}

The Quake-Catcher Network (QCN) is an expanding seismic array made possible by thousands of participants who volunteered time and resources from their computers to record seismic data using low-cost accelerometers (http://qcn.stanford.edu/; last accessed December 2014). Sensors based on Micro-Electromechanical Systems (MEMS) technology have rapidly improved over the last few years due to the demand of the private sector (e.g., automobiles, cell phones, and laptops). For strong-motion applications, low-cost MEMS accelerometers have promising features due to an increasing resolution and near-linear phase and amplitude response (Cochran, Lawrence, Christensen, and Jakka, 2009; Clayton et al., 2011; Evans et al., 2014).

Each volunteer computer monitors ground motion and communicates using the Berkeley Open Infrastructure for Network Computing (BOINC, Anderson, 2004). Using a standard short-term average, long-term average (STLA) algorithm (Earle and Shearer, 1994; Cochran, Lawrence, Christensen, Chung, 2009; Cochran, Lawrence, Christensen, and Jakka, 2009), volunteer computer and sensor systems detect abrupt changes in the acceleration recordings. Each time a possible trigger signal is declared, a small package of information containing sensor and ground-motion information is streamed to one of the QCN servers (Chung et al., 2011). Trigger signals, correlated in space and time, are then processed by the QCN server to look for potential earthquakes.

Former studies analyzed the reliability of the recorded ground motions (Cochran et al., 2011) as well as the speed and accuracy of earthquake magnitude and location determination (Chung et al., 2011; Lawrence et al., 2014) from QCN records. In Chile, $\sim 100$ sensors were installed after the 27 February $2010 M_{\mathrm{w}} 8.8$ earthquake to monitor its aftershocks (Chung et al., 2011). Trigger analysis found that sensor triggers were transferred from Chile to the QCN server in California, with an average latency of $\sim 5 \mathrm{~s}$. More than $90 \%$ of the triggers arrived in less than $8 \mathrm{~s}$ showing promising results for earthquake early warning. In New Zealand, 190 sensors were installed in Christchurch after the 3 September $2010 M_{\mathrm{w}} 7.2$ earthquake. Magnitude and location estimates were highly correlated with values obtained using the GeoNet strong-motion instruments (Chung et al., 2011). Other participant countries in the program include Taiwan (Liang et al., 2013), France, and Colombia.

Since 2009, Mexico has participated as an autonomous member of the QCN program, referred to locally as the Red Atrapa Sismos (RAS), with the installation of $\sim 150$ sensors (Fig. 1). Given the economic and technological conditions, Mexico is an excellent candidate country for the installation of low-cost accelerometers for real-time earthquake monitoring. A large number of moderate to megathrust earthquakes occur every year along the subduction zone that borders the entire west coast of the country (Fig. 2). These events pose a significant risk to the population of the entire country. For instance, in 1985 Mexico City was devastated by an $M_{\mathrm{w}} 8.1$ subduction zone earthquake, occurred more than $400 \mathrm{~km}$ from the capital.

In only two years, the number of seismic instruments installed as part of the QCN program in Mexico surpassed the number of seismic stations operated by the National Seismological Service (Servicio Sismológico Nacional [SSN]) array, which consists of $\sim 80$ broadband stations evenly distributed across the country. Even though the resolution of the network is limited to earthquakes that generate strong ground motions, the reach of the array shows increasing potential for earthquake monitoring at low cost for countries with limited economic resources for seismic studies.

\section{INSTALLATION}

Sensors have been deployed mainly along the southeast coast and in Mexico City (the latest map showing the distribution of sensors is available at http://www.ras.unam.mx; last accessed December 2014). During the first stage of the project, sensors reported data to the main server at Stanford University located in California, U.S.A. In 2012, a mirror server was installed at the 


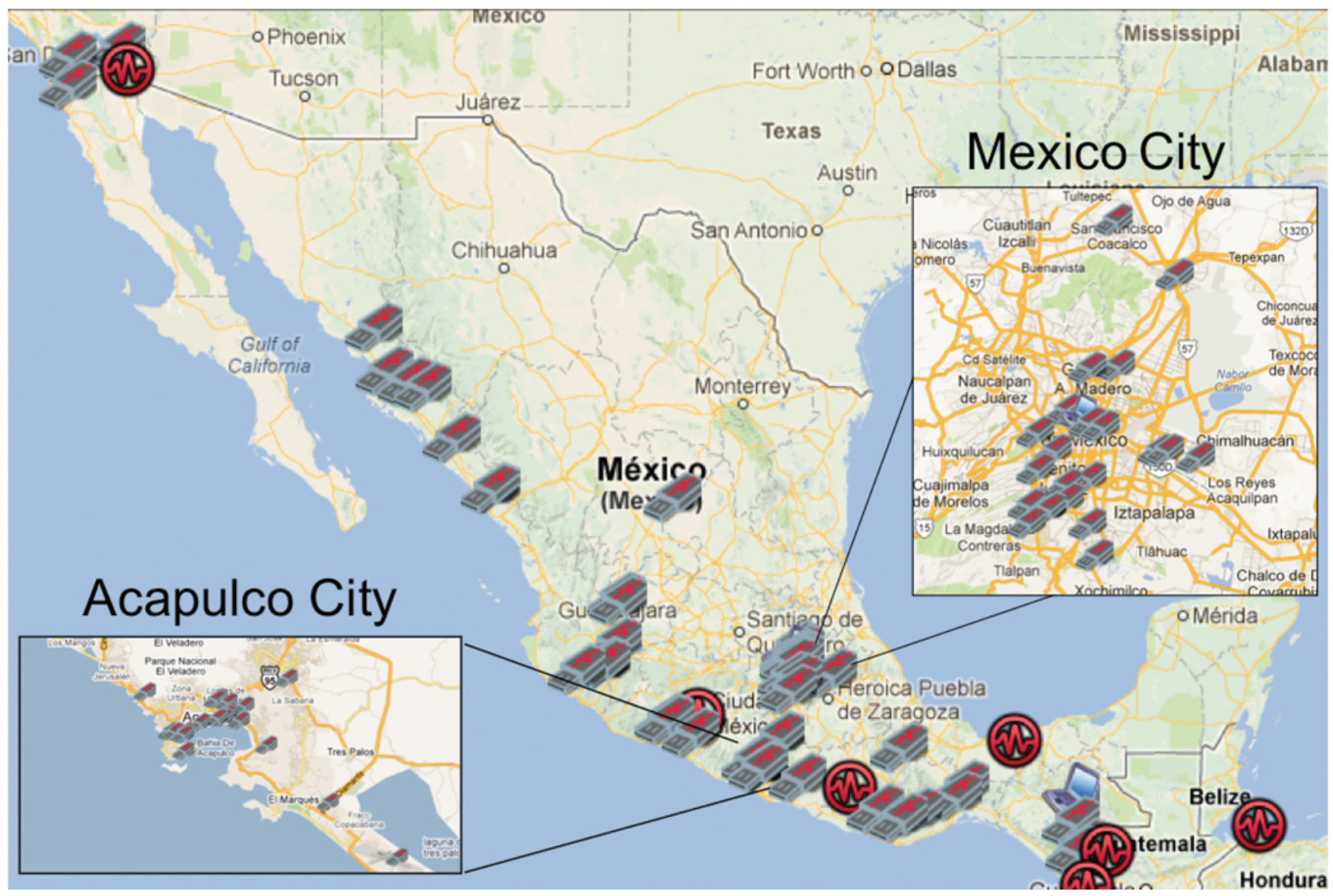

A Figure 1. Distribution of sensors in Mexico (April 2013). USB-like icons indicate external sensors. Laptop-like icons show internal sensors. Circles correspond to earthquakes $M_{\mathrm{w}}>3.5$ as reported by the U.S. Geological Survey (USGS).

main campus of the Autonomous National University of Mexico in Mexico City to provide redundancies to the system and allow independent testing of the algorithms.

Sensors operate under either trigger or continuous mode. In the trigger mode, the sensor data are saved in a small ring buffer until the STLA algorithm declares a trigger. The host computer then transmits a package of information to the server with the sensor identification information (sensor id, latitude and longitude, type of sensor) and the trigger data (trigger time and maximum peak ground acceleration for four consecutive $1 \mathrm{~s}$ time windows). Sensors operating in continuous mode locally record ground motions in $10 \mathrm{~min}$ intervals, and the waveforms are transferred periodically to the central server. Continuous mode allows recording for uninterrupted collection of the data that can be used for building response analysis (Kohler et al., 2013) and non-real-time studies (Cochran et al., 2011). Figure 3 shows the latency times for the RAS array in comparison with the latency times observed worldwide by $\mathrm{QCN}$ project. In Mexico, $90 \%$ of the trigger data reach the central computer within $8.1 \mathrm{~s}$. Although in Mexico there is some delay in the transmission of the data due to slower Internet connections, it does not significantly affect the performance of the system.

The RAS consists mainly of 16-bit O-Navi sensors and a smaller number of 12- or 14-bit Joy Warrior sensors. 16-bit sensors provide a larger detection range, increasing the earthquake detectability in areas of low sensor density and for small earthquakes $\left(M_{\mathrm{w}}<4.0\right)$. Sensors have been installed mostly at public institutions, namely schools, colleges, governmental offices, and hospitals. Installation at public institutions seeks to foster understanding of seismology among the general public and students in addition to providing a reliable Internet connection during working hours. In some cases, local businesses such as hotels and resorts were included in the program given their proximity to the Pacific coast. The majority of these sites have been chosen through scouting trips along the Pacific Coast of Mexico and electronic requests made by members of the public through the RAS website.

For better performance of the array, sensors are fixed permanently to the ground with either epoxy or instant glue and then covered with a translucent acrylic box. This simple setup reduces false triggers caused by accidental bumps and enhanced the participant engagement in project in comparison to simply taping the sensor to the ground as was done at the start of the project.

\section{SEISMIC RISK}

Mexico is located at the southern edge of the North American plate where it collides with the Cocos and Caribbean plates. 


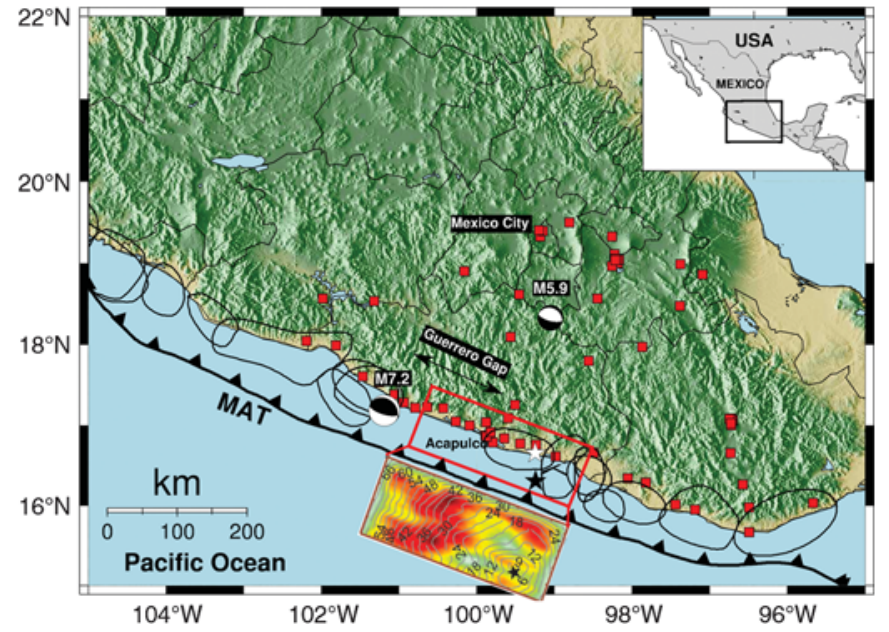

A Figure 2. Map of simulated Red Atrapa Sismos (RAS) stations (red squares) for the hypothetical $M_{\mathrm{w}} 8.2$ earthquake rupture along the Guerrero Gap. The red box shows the rupture slip (shown offset from the box) used for the synthetic scenario (Pérez-Campos et al., 2013). The white star marks the epicenter obtained by the inversion, whereas the black star indicates the location used in the computation of the synthetic seismograms. Focal mechanisms correspond to the epicentral location of the $M_{\mathrm{w}} 7.2$ Papanoa and the $M_{\mathrm{w}} 5.9$ Huitzuco earthquakes. Polygons indicate the location of the major ruptures in Mexico in the past 100 years (Kostoglodov and Pacheco, 1999). MAT, Middle America trench.

The subduction rate of the Cocos plate is between $\sim 50-100 \mathrm{~mm} / \mathrm{yr}$ along the Pacific coast of Mexico, whereas the Caribbean plate slips near the southern border with Guatemala and Belize at a rate of $20 \mathrm{~mm} / \mathrm{yr}$. Therefore, seismic potential for damaging megathrust earthquakes along the Pacific coast increases from the southern border with Guatemala up to the triple junction between the Rivera, Cocos, and North America plate. Figure 2 shows the rupture zones from some of the largest earthquakes recorded during the past 100 years and the location of the earthquakes analyzed in this study. Notice the segment of the trench, known as the Guerrero Gap, where no large earthquakes have been reported at least since the first decade of the twentieth century. This segment is also at the shortest distance between the seismogenic zone and Mexico City posing a potentially elevated risk for the Mexican capital.

Population density in Mexico is mainly concentrated inland around the Mexico City area ( 20 million people), although some important cities exist along the coast, such as Acapulco, Mazatlan, Puerto Vallarta, and so on. Nonetheless, ground motions are highly amplified at regional distances as dramatically demonstrated during the $1985 M_{\mathrm{w}}$ 8.1 Michoacán earthquake (Campillo et al., 1989). Human and economic losses from this earthquake still remain as the most devastating natural catastrophe in the history of Mexico. The earthquake, located on the Pacific Coast $>400 \mathrm{~km}$ southwest from the capital, caused seismic waves with dominant frequency that were trapped and amplified within the Mexico City basin (Anderson et al., 1986; Sánchez-Sesma et al., 1988; Singh et al., 1988; Ordaz and

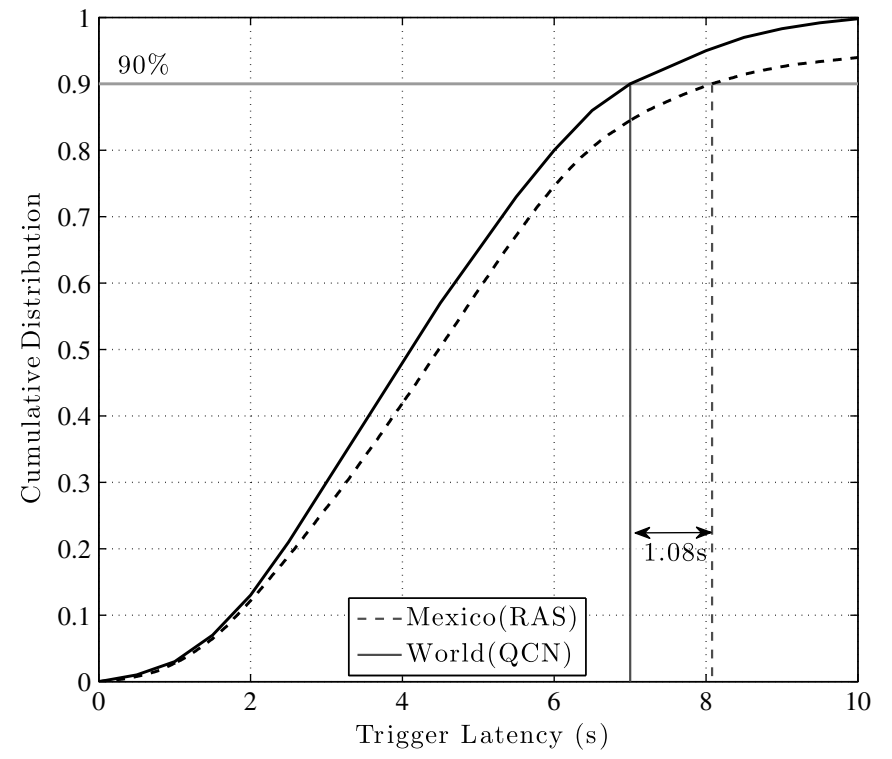

A Figure 3. Latency of the RAS array compared with the latency observed globally by the OCN.

Singh, 1992; Kanamori et al., 1993). The resonance of the basin caused the collapse of hundreds of 7-14 story buildings including modern apartment complexes and major hospitals.

Although large megathrust earthquakes have been historically considered the major seismic risk, intraslab earthquakes at the northern end of the subducted Cocos plate poses an increasing concern in the estimation of seismic hazard in central Mexico (Singh et al., 2014). Garcia et al. (2005) shows that intraslab earthquakes produce high peak ground accelerations due to a larger stress drop in comparison with interplate events. Response spectra for interplate earthquakes as recorded in Mexico City show higher amplitudes in the $0.1-2 \mathrm{~Hz}$ frequency range, whereas recordings from intraslab events are dominated by higher frequencies, $\mathrm{f}>2.5 \mathrm{~Hz}$ (Singh et al., 2013). Some consequences of the difference in the spectral amplitudes suggest that intraslab events represent a major risk for low-rise buildings ( $<4$ story) in comparison with the farther interplate events. These two types of events have now been recorded by the RAS array as discussed below.

\section{JUNE $2013 M_{\mathrm{w}}$ 5.9 EARTHQUAKE}

On 16 June 2013, a moderate intraslab normal-faulting earthquake ruptured $112 \mathrm{~km}$ south of Mexico City with a magnitude of $M_{\mathrm{w}} 5.9$ as reported by the SSN. This earthquake is one of the closest such events to Mexico City ever recorded. The broadband CU station, located at the Universidad Nacional Autónoma de México (UNAM)-Institute of Geophysics, recorded the second largest peak ground acceleration $(19.2 \mathrm{Gal})$ in the last 50 years, exceeded only by the catastrophic 1985 earthquake (Singh et al., 2014). Intensities in the city were comparable with the intensities generated by larger $\left(M_{\mathrm{w}}>7.0\right)$ thrust earthquakes along the subduction in- 


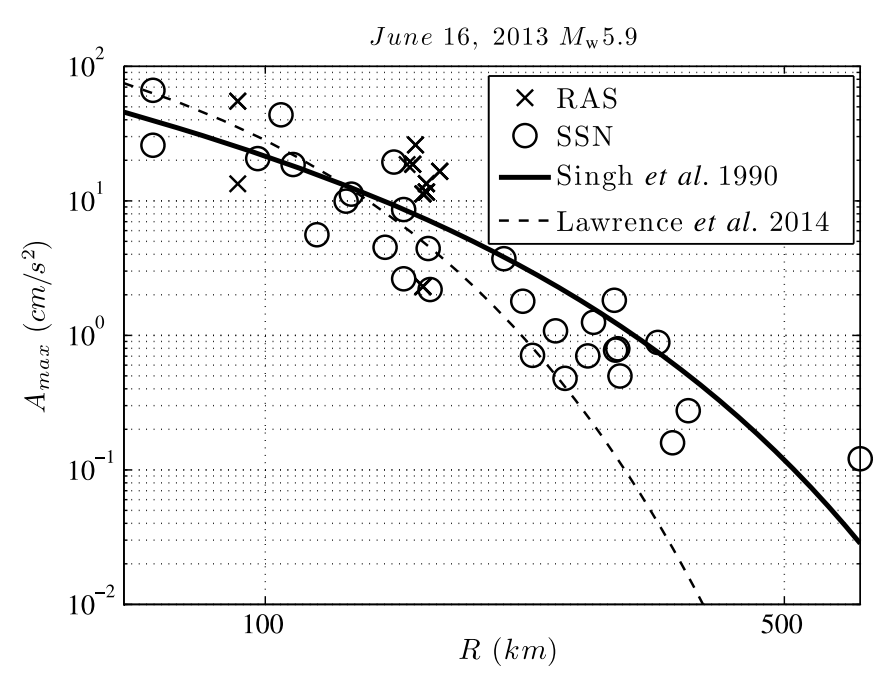

$\Delta$ Figure 4. Attenuation law for intraslab earthquakes in central Mexico. Crosses show the $A_{\max }$ from the RAS sensors, and circles show the National Seismic Network sensors.

terface. Ground shaking was widely described by the population as extremely strong. Figure 4 shows a comparison between the $A_{\max }\left(\sqrt{\left(\mathrm{PGA}_{\mathrm{NS}}^{2}+\mathrm{PGA}_{\mathrm{EW}}^{2}\right) / 2}\right)$ recordings of the RAS array and the $A_{\max }$ accelerations recorded by the SSN local network. Performance of RAS sensors is consistent with that of the SSN instruments. The solid line indicates the attenuation law for intraslab events obtained using a historical dataset (Garcia et al., 2005). This type of earthquake shows larger stress drops and amplitudes at high frequencies in comparison with intracrust earthquakes with similar magnitudes in this area (Singh et al., 2013).

At the time of the earthquake, most of the active sensors happened to be in the lake-bed zone of Mexico City. The resulting ShakeMap was released automatically $33 \mathrm{~s}$ after the earthquake, Figure 5a shows the ShakeMap obtained using the RAS network. Higher seismic intensities correlate well with the areas where amplified peak ground accelerations are expected due to the low-velocity properties of the near-surface soil. However, the resulting location and magnitude were not well constrained. The original algorithm used a $200 \mathrm{~km}$ correlation distance for the triggers. A posteriori examination of the results showed that the limiting distance was not sufficiently large to provide an accurate estimate of the epicenter location and consequently its magnitude. The detection algorithms were originally developed using relatively small source-station distances (10-100 km) and small events $\left(M_{\mathrm{w}} \sim 4-5\right)$ (e.g., Chung et al., 2011; Lawrence et al., 2014). Thus, the performance was poor for the source-station distributions for this event. Figure $5 \mathrm{~b}$ shows the revised ShakeMap obtained by rerunning the event retrospectively, using a maximum correlation distance between triggered sensors of $400 \mathrm{~km}$. As a result, the accuracy in the location of the event significantly improved to within a few kilometers from the location provided by the SSN and reported by the U.S. Geological Survey (USGS).

\section{APRIL $2014 M_{w} 7.2$ PAPANOA EARTHOUAKE}

The 18 April $2014 M_{\mathrm{w}} 7.2$ Papanoa earthquake ranks among the largest earthquakes recorded by the RAS array. It ruptured a segment of the Pacific trench, just northwest of the Guerrero Gap. The event caused moderate damage in the epicentral area and in Mexico City due to amplification of the seismic waves in the sedimentary basin that underlies the city. The Mexican earthquake early warning system successfully triggered an alarm in Mexico City, $68 \mathrm{~s}$ before the surface waves reached the capital. The event occurred during a major holiday in Mexico, Good Friday, which caused many of the computers located at schools and public offices to be out of service at the time of the earthquake. However, a sufficient number of sensors were active at regional distances and in Mexico City. The occurrence of the event under these circumstances provided an excellent opportunity to test the RAS array under a low level of volunteer participation. Despite the sparseness of the network, the system successfully estimated the magnitude and location. Nonetheless, a maximum correlation distance of $400 \mathrm{~km}$ was required to overcome the lack of near-epicenter sensors. Figure $6 \mathrm{a}$ shows the location of the sensors used in the inversion of the data and all sensors that reported waveform data to the RAS server hours after the event. Because of the large distance between the source and many of the sensors, it took a significant amount of time (over a minute) for the system to issue an initial location and magnitude for the event. However, the event demonstrated a robust detection for a $100 \mathrm{~km}$ sparse network.

Figure $6 \mathrm{~b}$ shows the maximum peak ground accelerations for the sensors used in the inversion of the data. Remarkably, data reported from the sensors located in the state of Colima and in Ciudad Guzman, Jalisco, $\sim 350 \mathrm{~km}$ northwest of the epicenter; roughly at the same distance as Mexico City, show accelerations that exceed the peak accelerations in Mexico City basin. Data from these sensors were not used in the original earthquake location due to the correlation distance limitation in the location algorithm. However, large acceleration records show evidence of possible zones where seismic hazard may be underestimated due to the lack of seismic instrumentation.

\section{MAGNITUDE 8.2 EARTHOUAKE SCENARIO}

The Guerrero Gap is a segment of the subduction zone along the Pacific Coast of Mexico well known for the lack of large ruptures in the past 100 years. It is believed to be the highest seismic risk segment in Mexico with the potential to produce an earthquake with a magnitude at least as high as $M_{\mathrm{w}}$ 8.1. The rupture zone is $\sim 100 \mathrm{~km}$ closer to Mexico City than the damaging 1985 Michoacán earthquake, thereby it may induce ground motions in the Mexico City basin with amplitudes 2 or 3 times larger than those observed in 1985 for periods shorter than 2 s (Kanamori et al., 1993). Furthermore, the port city of Acapulco, one of the main resort cities and commercial hubs of Mexico, lies on the edge of the seismic gap where large economic and human losses are expected in case of a rupture of this segment. 
(a)

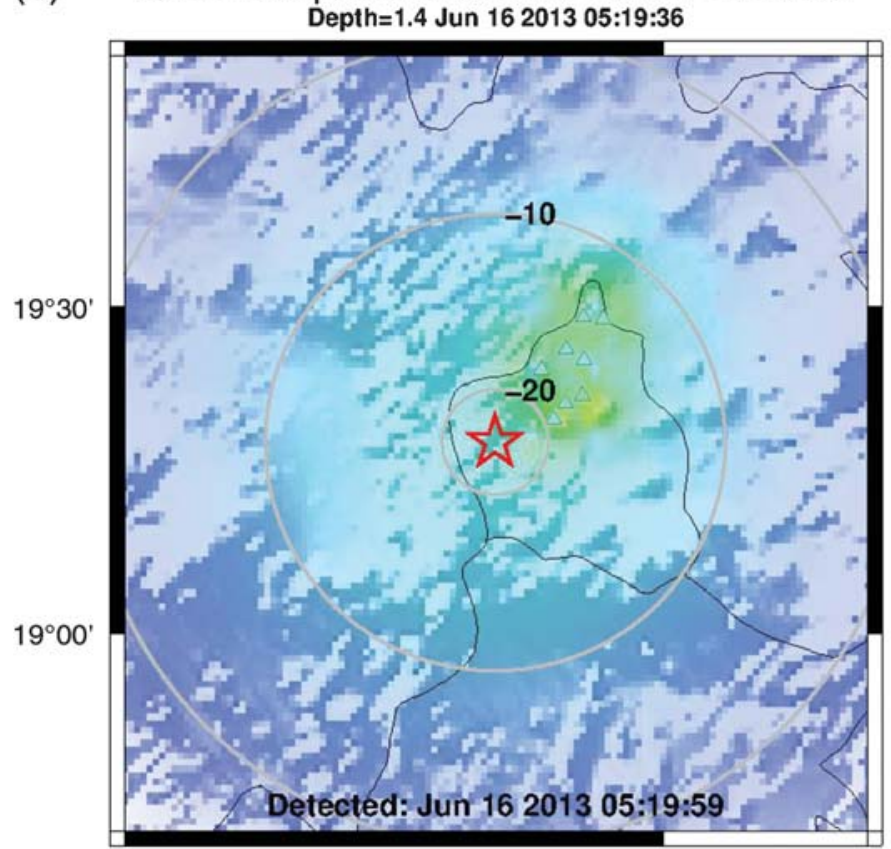

$-99^{\circ}$ (b)

QCN Earthquake - M6.0 Lon $=-99.31$ Lat $=18.09$

Depth=6.1 Jun 162013 05:18:57

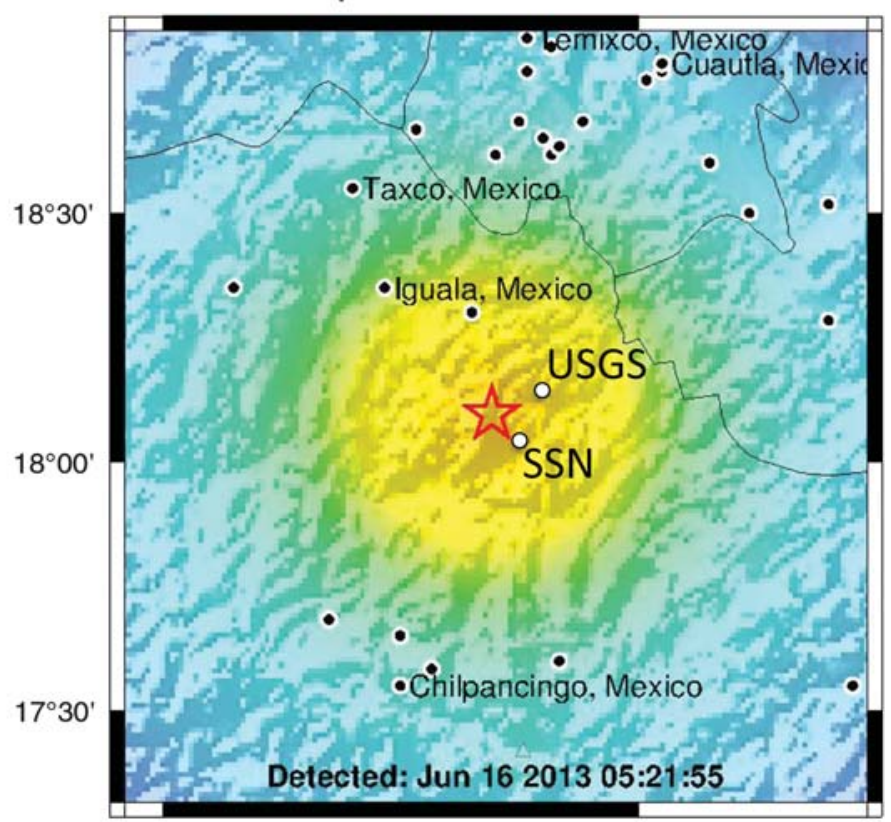

$-100^{\circ}$ $-99^{\circ}$

\begin{tabular}{|c|c|c|c|c|c|c|c|c|c|}
\hline $\begin{array}{c}\text { PERCEIVED } \\
\text { SHAKING }\end{array}$ & Not felt & Weak & Light & Moderate & Strong & Very strong & Severe & Violent & Extreme \\
\hline $\begin{array}{c}\text { POTENTIAL } \\
\text { DAMAGE }\end{array}$ & none & none & none & Very light & Light & Moderate & Moderate/Heavy & Heavy & Very Heavy \\
\hline PEAK ACC.(\%g) & $<.17$ & $\mathbf{. 1 7 - 1 . 4}$ & $\mathbf{1 . 4 - 3 . 9}$ & $\mathbf{3 . 9 - 9 . 2}$ & $\mathbf{9 . 2 - 1 8}$ & $18-34$ & $34-65$ & $65-124$ & $>124$ \\
\hline PEAK VEL.(cm/s) & $<0.1$ & $0.1-1.1$ & $1.1-3.4$ & $3.4-8.1$ & $\mathbf{8 . 1 - 1 6}$ & $\mathbf{1 6 - 3 1}$ & $\mathbf{3 1 - 6 0}$ & $\mathbf{6 0 - 1 1 6}$ & $>\mathbf{1 1 6}$ \\
\hline $\begin{array}{c}\text { INSTRUMENTAL } \\
\text { INTENSITY }\end{array}$ & $\mathrm{I}$ & II-III & IV & V & VI & VII & VIII & IX & X+ \\
\hline
\end{tabular}

A Figure 5. (a) ShakeMap released by the RAS shortly after the 16 June $2013 M_{\mathrm{w}} 5.9$ earthquake. (b) Revised map obtained using an offline version of the code, showing an accurate location and magnitude of the event. Red star indicates estimated event epicenter, and colors indicate estimated peak shaking intensities. Empty circles show the locations reported by the SSN and the USGS, respectively.
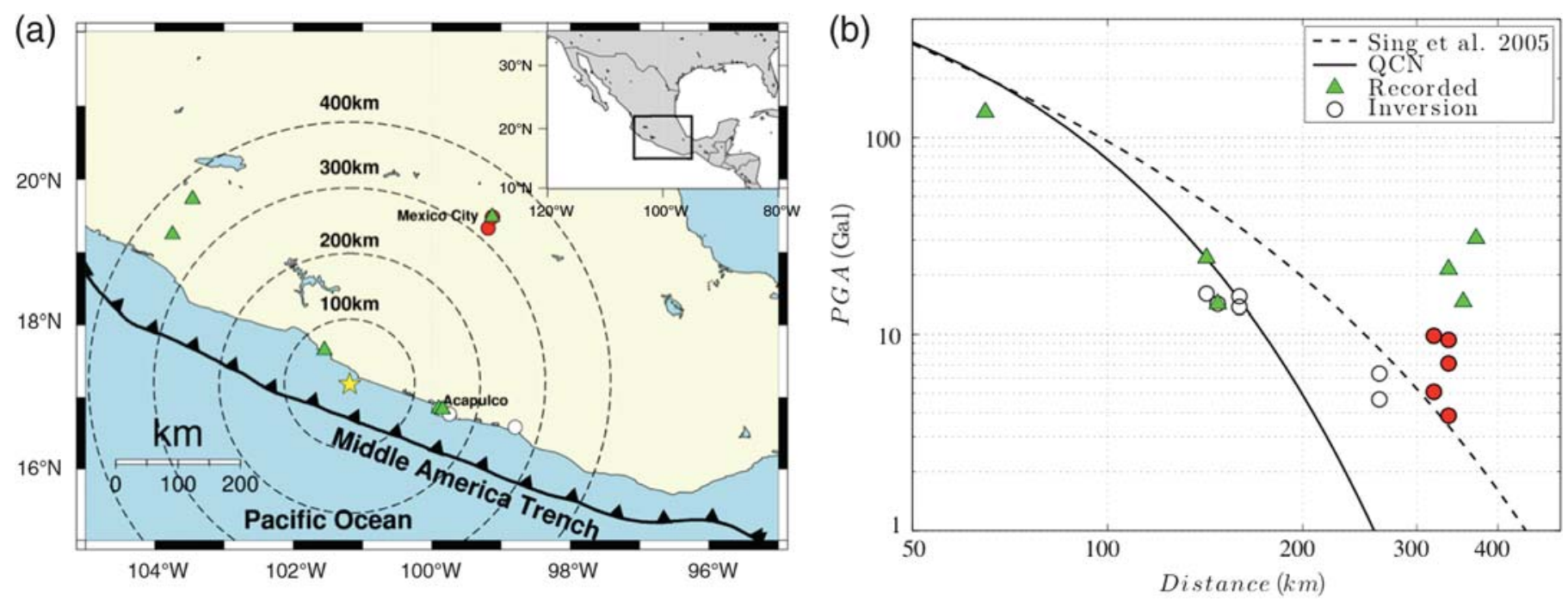

A Figure 6. (a) Distribution of reported triggers from the RAS array for the $M_{\mathrm{w}}$ 7.2 Papanoa earthquake. Red circles indicate the triggers used in the magnitude and location estimation, these sensors provide the best-fitting data. White circles show triggers outside the Mexico City basin. Triangles show triggers retrieved by the system after the earthquake but not used in the inversion of the data. (b) Maximum peak ground acceleration recordings as a function of distance to the epicenter. Solid lines indicate the attenuation law for magnitude 7.2 earthquakes. Symbols and color coding are the same as in (a). 


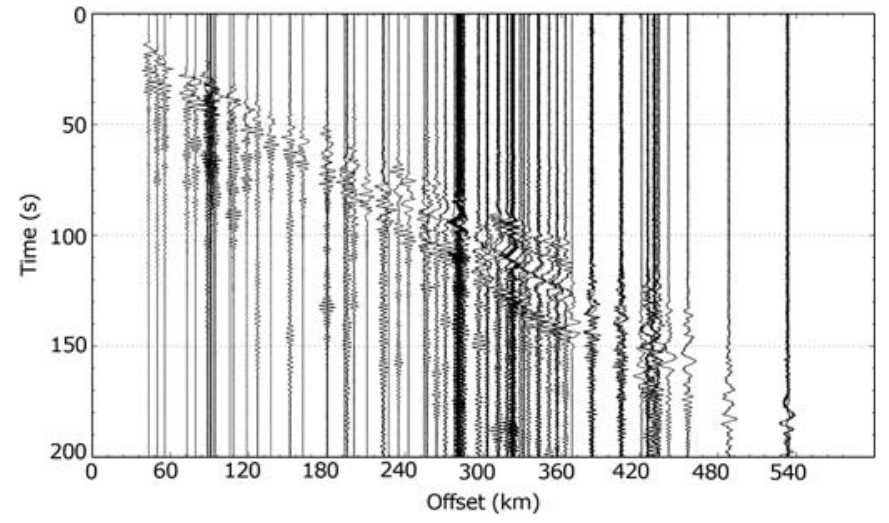

$\Delta$ Figure 7. Vertical-component simulated traces for an $M_{\mathrm{w}} 8.2$ scenario. White noise was added to each of the traces to count on the electronic noise of the sensors.

Following Cruz-Atienza et al. (2011), we generated synthetic seismograms to test the response of the RAS array for an $M_{\mathrm{w}} 8.2$ scenario earthquake with these features by means of a parallel finite-difference code (Olsen et al., 2009) in a heterogeneous crustal model (Iglesias et al., 2010). The fault area is $84 \mathrm{~km}$ long and $42 \mathrm{~km}$ wide and has a final-slip distribution stochastically generated using a spatial random field modulated by a von Karman autocorrelation function. Local rupture velocities (i.e., source rupture times) are variable and were determined as a function of local final slips with respect to a mean value of $2.8 \mathrm{~km} / \mathrm{s}$. Slip rate time histories are the dynamic-rupture consistent Yoffe functionals introduced by Tinti et al. (2005). The hypocenter was fixed at $16.307^{\circ} \mathrm{N}$, $-99.240^{\circ} \mathrm{W}$, and $7 \mathrm{~km}$ depth. There is an average slip on the fault of $2.0 \mathrm{~m}$ and a maximum of $4.5 \mathrm{~m}$. Details on the source generation can be found in Pérez-Campos et al. (2013).

We examine the simulated data from 93 stations, which correspond to the current configuration of the National Seismic Network and the Mexico City Strong Motion Array. Figure 2 shows the distribution of stations used in the synthetic model. White noise is added to each of the sensors to account for electronic noise and random perturbations. Figure 7 shows the simulated vertical component of the seismic traces generated. The data are fed into an offline version of the QCN software, which produces a hypothetical ShakeMap and location. Network delays are also included in the simulations based on the trigger time information collected during the past two years (Lawrence et al., 2014).

To test the possible outcome of the system in the event of a large rupture, we randomly select a subset of $N$ stations from the original data set to emulate the fluctuations of the active sensors in the network. The RAS array depends heavily on the volunteer participation to keep their computers powered on and connected to the Internet. Additional misses may be caused by power and Internet disruption due to intense shaking near the epicentral area. By selecting an assemblage of 100 sets of $N$ stations, we obtain a statistical test of the performance of the array as a function of the number of active sensors.

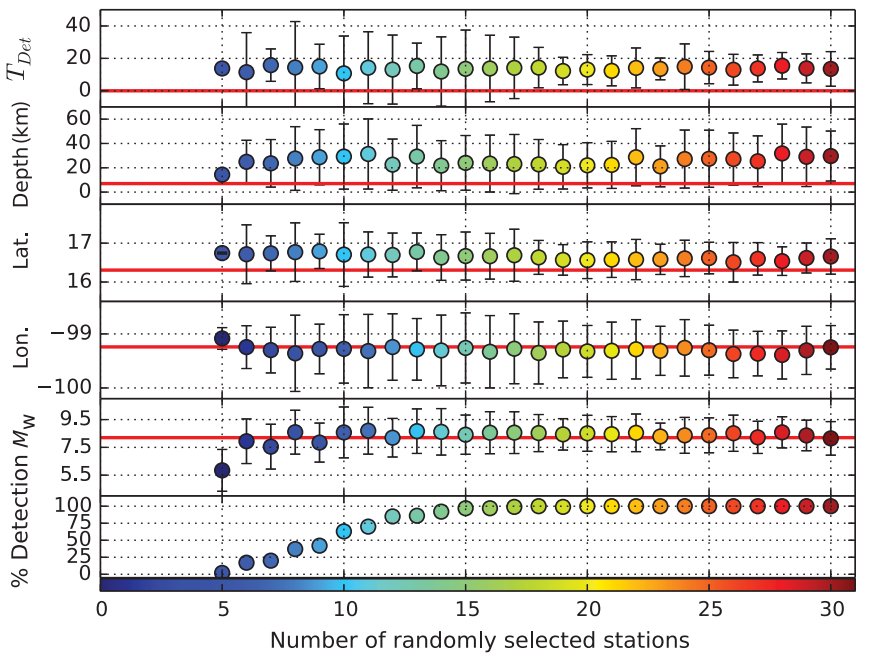

$\Delta$ Figure 8. Performance of the array for the $M_{\mathrm{w}} 8.2$ scenario. Red Lines indicate the theoretical latitude, longitude, depth, and magnitude used for the computation of the synthetic scenario. $T_{\text {Det }}$ is the difference between the calculated earthquake time and the hypothetical start time of the earthquake. The \% detection shows the probability at which a randomly selected set of $N$ stations yields a detection.

Figure 8 summarizes the results of the test. The percentage of detections is the minimum number of stations needed for the system to correlate the incoming triggers as a possible event. In this case, the maximum correlation distance among sensor is set to $400 \mathrm{~km}$ to include triggers in areas such as Mexico City, where the sensor density is greater and strong shaking is expected. The rate of detection increases linearly as the number of $N$ active sensors that trigger during the earthquake increases from a minimum of 5 sensors up to approximately 15 sensors; if more than 15 sensors record an event then the percentage of events detected is essentially $100 \%$. Magnitude estimates fit well within one standard deviation from the theoretical value of $M_{\mathrm{w}} 8.2$ simulation. On the other hand, the hypocentral location of the event is shifted from the original position as a consequence of the large dimensions of the rupture. Latitude is generally well resolved within less than one standard deviation, even with a small number of sensors. However, the longitude estimate is biased northward of the scenario epicenter, likely due to the fact that no sensors are located south of the rupture area. Depth is overestimated by the location algorithm, which provides a mean depth of the rupture. The value of $T_{\mathrm{dec}}$ indicates the difference between the theoretical start of the earthquake and the time to obtain an initial solution to the inversion algorithm. On average, the system reports the origin time of the earthquake $\sim 15 \mathrm{~s}$ after the actual time as a consequence of the error in the latitude and depth estimate.

A major challenge in the accuracy of the algorithms lies in the fact that predicted peak ground accelerations in Mexico City (and possibly other areas) greatly exceed predicted values by standard attenuation laws. The select simulation does not 
include such an effect, but it does provide a metric for the expected outcome for a large earthquake scenario.

\section{DISCUSSION AND CONCLUSIONS}

The RAS is a strong-motion seismic network that has rapidly grown in Mexico in the last few years. Unlike other strong-motion networks, the RAS array fully streams real-time data through the Internet and produces online intensity ShakeMaps within a few seconds of an earthquake. The capabilities of the system are found through an examination of the performance of the network dur$\operatorname{ing} M_{\mathrm{w}} 5.9$ and $M_{\mathrm{w}} 7.2$ earthquakes that occurred in the past two years and an expected $M_{\mathrm{w}} 8.2$ scenario.

The intraslab earthquake (16 June 2013) recorded by the array shows that maximum correlation distance drastically limits the location of the system in cases where there is poor or null sensor density around the epicentral area. By increasing the maximum correlation threshold (from 200 to $400 \mathrm{~km}$ ), it was possible to improve the location and magnitude significantly for this event. Although intraslab earthquakes are relatively infrequent in comparison with the interplate earthquakes, they occur at closer distances to populated areas, which may pose an underestimation of the seismic risk in Mexico City (Iglesias et al., 2002; Singh et al., 2013).

The Papanoa earthquake was a powerful event that was recorded by a relatively small number of instruments. The recordings from these events show significant amplification factors not only in Mexico City but also in other areas of the country where seismic studies have been limited by the lack of strong-motion instrumentation.

The numerical simulation shows the possible outcome for a large earthquake $\left(M_{\mathrm{w}}>7.5\right)$ the recurrence time of which is $\sim 30$ years (Iglesias et al., 2002). For the magnitude $M_{\mathrm{w}} 8.2$ scenario, the expected ground motions and location are accurately predicted by an offline version of the code. Although the location of the onset (epicenter) of the rupture was not properly resolved, it lay within the rupture zone. The response of the array shows promising capabilities for detecting a damaging earthquake using a sparse network with spacing between sensors of even hundreds of kilometers.

Performing a quick characterization of strong-motion accelerations can contribute to an efficient emergency response in the event of a major earthquake in Mexico. In particular, the deployment of a low-cost, real-time seismic network shows an important advance of the seismic monitoring capabilities of Mexico. Evaluation of the current algorithms shows the present configuration of instruments can produce reliable ShakeMaps in short periods of time. In addition, we observed that site effects do not significantly influence the location and magnitude estimation of events. Testing of the system using numerical simulation suggests a robust performance for large and damaging earthquakes. Bias in the time and location estimates comes from complexity of the source and an irregular distribution of sensors.

Although site effects in Mexico City are well known, and widely studied, large amplification factors may exist in other areas that are currently undocumented. The RAS arrays open a new opportunity to analyze site effects in areas of the country with no traditional seismic instrumentation due to lack of infrastructure and economic relevance for the country. Monitoring site effects plays an important role in understanding the propagation of seismic waves and for the correct design of the construction codes. $\mathbf{<}$

\section{ACKNOWLEDGMENTS}

The authors would like to thank Susan Hough, Rob Graves, Raul Valenzuela Wong, and an anonymous reviewer for their valuable comments and suggestions that significantly improved the manuscript. Furthermore, we want to thank dozens of volunteers and students that participate in the Quake-Catcher Network (QCN) program in Mexico for their support and invaluable assistance. Installation and maintenance of the array was funded by the Grants PAPIIT IB101312-2, UC MEXUSCONACYT CN-09-315, and NSF EAR-1027802.

\section{REFERENCES}

Anderson, D. P. (2004). BOINC: A system for public-resource computing and storage rep., 5th IEEE/ACM International Workshop on Grid Computing, Pittsburgh, Pennsylvania, 8 November 2004.

Anderson, J. G., P. Bodin, J. N. Brune, J. Prince, S. K. Singh, R. Quaas, and M. Onate (1986). Strong ground motion from the Michoacán, Mexico, earthquake, Science 233, no. 4768, 1043-1049.

Campillo, M., J. C. Gariel, K. Aki, and F. J. Sánchez-Sesma (1989). Destructive strong ground motion in Mexico City: Source, path, and site effects during great 1985 Michoacán earthquake, Bull. Seismol. Soc. Am. 79, no. 6, 1718-1735.

Chung, A. I., C. Neighbors, A. Belmonte, M. Miller, H. H. Sepulveda, C. Christensen, R. S. Jakka, E. S. Cochran, and J. F. Lawrence (2011). The Quake-Catcher Network rapid aftershock mobilization program following the 2010 M 8.8 Maule, Chile earthquake, Seismol. Res. Lett. 82, no. 4, 526-532.

Clayton, R., T. Heaton, M. Chandy, A. Krause, M. Kohler, J. Bunn, R. Guy, M. Olson, M. Faulkner, M.-H. Cheng, L. Strand, R. Chandy, D. Obenshain, A. Liu, and M. Aivazis (2011). Community Seismic Network, Ann. Geophys. 54, no. 6, doi: 10.4401/ag-5269.

Cochran, E. S., J. F. Lawrence, C. Christensen, and A. Chung (2009). A novel strong motion seismic network for community participation in earthquake monitoring, IEEE Instrum. Meas. Mag. 12, 8-15.

Cochran, E. S., J. F. Lawrence, C. Christensen, and R. Jakka (2009). The Quake-Catcher Network: Citizen science expanding seismic horizons, Seismol. Res. Lett. 80, 26-30.

Cochran, E. S., J. F. Lawrence, A. Kaiser, B. Fry, A. Chung, and C. Christensen (2011). Comparison between low-cost and traditional MEMS accelerometers: A case study from the M 7.1 Darfield, New Zealand, aftershock deployment, Ann. Geophys. 54, no. 6, 728-737.

Cruz-Atienza, V. M., V. Hjörleifsdóttir, and A. Rocher (2011). Simulando un M 8.2 en la brecha de Guerrero, Reunión Anual 2011, Unión Geofísica Mexicana, GEOS 31, 150.

Earle, P. S., and P. M. Shearer (1994). Characterization of global seismograms using an automatic picking algorithm, Bull. Seismol. Soc. Am. 84, 366-376.

Evans, J. R., R. M. Allen, A. I. Chung, E. S. Cochran, R. Guy, M. Hellweg, and J. F. Lawrence (2014). Performance of several low-cost accelerometers, Seismol. Res. Lett. 85, no. 1, 147-158.

Garcia, D., S. K. Singh, M. Herráiz, M. A. Ordaz, and J. Pacheco (2005). Inslab earthquakes of Central Mexico: Peak ground-motion parameters and response spectra, Bull. Seismol. Soc. Am. 95, no. 6, 22722282. 
Iglesias, A., R. W. Clayton, X. Pérez-Campos, S. K. Singh, J. F. Pacheco, D. García, and C. Valdés-González (2010). $S$ wave velocity structure below central Mexico using high-resolution surface wave tomography, J. Geophys. Res. 115, no. B06307, doi: 10.1029/2009JB006332.

Iglesias, A., S. K. Singh, J. F. Pacheco, and M. Ordaz (2002). A source and wave propagation study of the Copalillo, Mexico earthquake of 21 July, $2000\left(M_{\mathrm{w}}=5.9\right)$ : Implications for seismic hazard in Mexico City from inslab earthquakes, Bull. Seismol. Soc. Am. 92, 885-895.

Kanamori, H., P. C. Jennings, S. K. Singh, and L. Astiz (1993). Estimation of strong ground motions in Mexico City expected for large earthquakes in The Guerrero Seismic Gap, Bull. Seismol. Soc. Am. 83, no. 3, 811-829.

Kohler, M. D., T. H. Heaton, and M. H. Cheng (2013). The Community Seismic Network and Quake-Catcher Network: Enabling structural health monitoring through instrumentation by community participants, in Sensors and Smart Structures Technologies for Civil, Mechanical, and Aerospace Systems 2013, J. P. Lynch, C-B. Yun, and K-W. Wang (Editors), Proc. of SPIE, Vol. 8692, 86923X.

Kostoglodov, V., and J. F. Pacheco (1999). Cien años de sismicidad en México, http://usuarios.geofisica.unam.mx/vladimir/sismos/100a\% F1os.html (last accessed December 2014).

Lawrence, J. F., E. S. Cochran, A. Chung, A. Kaiser, C. M. Christensen, R. Allen, and M. Taufer (2014). Rapid earthquake characterization using MEMS accelerometers and volunteer hosts following the M 7.2 Darfield, New Zealand, earthquake, Bull. Seismol. Soc. Am. 104, no. 1, 184-192.

Liang, W., W. Lee, K. H. Chen, E. H. Yen, J. F. Lawrence, C. Lin, and C. Chang (2013). Extracting the building response with QCN-Taiwan sensor data: Application to the building of Science Education Center, National Taiwan Normal University, in $A G U$ Fall Meeting Abstracts, San Francisco, California, Vol. 1, 2415.

Olsen, K. B., S. M. Day, L. A. Dalguer, J. Mayhew, Y. Cui, J. Zhu, V. M. Cruz-Atienza, D. Roten, P. Maechling, T. H. Jordan, D. Okaya, and A. Chourasia (2009). ShakeOut-D: Ground motion estimates using an ensemble of large earthquakes on the southern San Andreas fault with spontaneous rupture propagation, Geophys. Res. Lett. 36, L04303, doi: 10.1029/2008GL036832.

Ordaz, M., and S. K. Singh (1992). Source spectra and spectral attenuation of seismic waves from Mexican earthquakes, and evidence of amplification in the hill zone of Mexico City, Bull. Seismol. Soc. Am. 82, no. 1, 24-43.

Pérez-Campos, X., D. Melgar, S. K. Singh, V. Cruz-Atienza, A. Iglesias, and V. Hjörleifsdóttir (2013). Rapid estimation of fault parameters for tsunami warning along the Mexican subduction zone: A scenario earthquake in the Guerrero Seismic Gap, Seismol. Res. Lett. 84, no. 3, 474-484.

Sánchez-Sesma, F., S. Chavez-Perez, M. Suarez, M. A. Bravo, and L. E. Perez-Rocha (1988). Mexico earthquake of September 19, 1985On the seismic response of the valley of Mexico, Earthq. Spectra 4, no. 3, 569-589.

Singh, S. K., J. Lermo, T. Dominguez, M. Ordaz, J. M. Espinosa, E. Mena, and R. Quaas (1988). Mexico earthquake of September 19, 1985-
A study of amplification of seismic waves in the valley of Mexico with respect to a hill zone site, Earthq. Spectra 4, no. 4, 653-673.

Singh, S. K., M. Ordaz, X. Pérez-Campos, and A. Iglesias (2013). Intraslab versus interplate earthquakes as recorded in Mexico City: Implications for seismic hazard, Earthq. Spectra, doi: 10.1193/ $110612 \mathrm{EQS324M}$.

Singh, S. K., X. Pérez-Campos, V. H. Espíndola, V. M. Cruz-Atienza, and A. Iglesias (2014). Intraslab earthquake of 16 June 2013 ( $M_{\mathrm{w}}$ 5.9), one of the closest such events to Mexico City, Seismol. Res. Lett. 85, no. 2, 268-277.

Tinti, E., E. Fukuyama, A. Piatanesi, and M. Cocco (2005). A kinematic source-time function compatible with earthquake dynamics, Bull. Seismol. Soc. Am. 95, no. 4, 1211-1223, doi: 10.1785/0120040177.

Luis A. Dominguez

National School for Professional Studies Campus Morelia, UNAM Antigua Carretera a Patzcuaro No. 8701 Colonia Ex-Hacienda de San Jose de la Huerta C.P. 58190 Michoacán, México ladominguez@geofisica.unam.mx

Battalgazi Yildirim Jesse F. Lawrence Stanford University 397 Panama Mall Mitchell Building 360 Stanford, California 94305-2215 U.S.A.

Allen L. Husker Carl Christensen Victor M. Cruz-Atienza Instituto de Geofísica, UNAM Circuito de la Investigación Cientifica s/n Ciudad Universitaria, Delegación Coyoacán C.P. 04510, México D.F.

\author{
Elizabeth Cochran \\ U.S. Geological Survey \\ 525 \& 535 South Wilson Street \\ Pasadena, California 91106-3212 U.S.A.
}

Published Online 11 March 2015 